\title{
Enfoques sobre el reclutamiento forzado de niños, niñas y adolescentes ${ }^{1}$
}

Por Kelly Jiménez A. ${ }^{2}$

\section{Introducción}

4 n la antigüedad, cuando los conflictos no contaban con suficiente personal para los grupos armados se recurría a la población infantil y juvenil. Incluso para la conformación de estos grupos se incentivaron los nacimientos de niños como a una capacitación en defensa y en armas para menores. En el siglo XIX se empezó a reglamentar la guerra en el uso de la fuerza, de métodos y medios y el impacto en las personas que no participan en los conflictos armados, entre muchas otras prácticas de legitimación.

1 El presente artículo de investigación es presentado como opción de grado para obtener el título de Magister en Derechos Humanos y Derecho Internacional de los Conflictos Armados de la Escuela Superior de Guerra, siendo producto del proyecto de investigación "Estrategias para enfrentar los retos de la sociedad y de las Fuerzas Militares de Colombia para la construcción y consolidación de la paz: Derechos Humanos y DICA como instrumento" vinculado al grupo de investigación "DDHH, DICA y Justicia” inscrito en Colciencias. Para el desarrollo de este artículo se contó con la tutoría del Profesor Ricardo Esquivel, PhD en Historia.

Artículo recibido en enero de 2016.

Artículo aprobado en marzo de 2016.

2 Candidata a Magister en Derechos Humanos y Derecho Internacional de los Conflictos Armados, Escuela Superior de Guerra. Pregrado en Filosofía, Universidad de La Salle. 
Con instrumentos como el Código Lieber de 1863 los estados empezaron a formalizar las conductas permitidas a los integrantes de sus ejércitos; aunque estas iniciativas solo se enfocaron en reglamentar las hostilidades - en un tiempo y en un espacio del conflicto armado, y dependieron de la voluntad de los estados confrontados. Con los Convenios de Ginebra (1948) hubo mayor preocupación por la participación de la población civil y el impacto sobre esta. Durante la Guerra Fría , en los conflictos armados, el reclutamiento pasó de ser únicamente para la defensa de un Estado a una práctica mediada por intereses particulares y de carácter ilegal. El reclutamiento de niños, niñas y adolescentes (en adelante NNA) adquirió un carácter negativo cuando se intensificaron los grupos armados ilegales. Por eso, en los dos Protocolos Adicionales (1977) de dichos convenios se estableció que las personas menores de quince años no debían participar directamente en las hostilidades de carácter nacional e internacional. ${ }^{3}$

En Colombia, en 1991, con la ratificación de la Convención de los Derechos de los Niños, hubo mayor preocupación por la participación de NNA en el conflicto armado y su impacto sobre ellos. El anterior panorama lleva a preguntar: ¿cuáles son los enfoques normativos y conceptuales sobre el reclutamiento forzado de NNA en el conflicto armado colombiano? Para responder a esta pregunta este artículo identificará algunos de los enfoques conceptuales y normativos en torno al reclutamiento forzado de NNA por los grupos armado ilegales.

Sobre el reclutamiento forzado en Colombia existen diversas publicaciones con perspectiva psicosocial , jurídica y sociopolítico, en su mayoría dedicadas a la caracterización y a las prácticas del problema ${ }^{4}$.

Protocolo Adicional I, artículo 77; Protocolo Adicional II, artículo 4 (CICR, 1977).

Perspectiva psicosocial: ICBF (2014); Lara \& Delgado (2010) y Wainryb (2011). Perspectiva jurídica: Coalico \& CCJ (2013); Ila (2009); Mariño (2012); Mejía (2012); Montalvo (2010); Ramírez (2010) y Tirado (2013). Perspectiva sociopolítica: Arjona y Kalyvas (2008); Gutiérrez (2010); Mago (2011); ODDR (2014); Pachón (2009); Reyes (2013) y Springer (2012). 
Pero, por el contrario, el presente artículo se basa en una investigación exploratoria para identificar algunos aspectos que son constantes sobre el reclutamiento forzado de NNA. Para el desarrollo de este enfoque se tuvo en cuenta, en gran medida, el método sistemático que permite agrupar algunos instrumentos normativos sobre dicho reclutamiento. Es decir, es una investigación de tipo cualitativo documental.

Los alcances de este artículo se restringen al reclutamiento forzado de NNA en el conflicto armado colombiano; y, al tener en cuenta que la existencia de este tipo de reclutamiento es propia del conflicto, no se toma un periodo de tiempo específico. En correlación con lo anterior, también se sugiere la participación de los NNA víctimas de dicho reclutamiento en el proceso de reintegración y reconciliación como responsables sociales. En consecuencia, el artículo no pretende establecer una línea jurisprudencial, ni un análisis exegético, ni establecer la evolución de las normas sobre reclutamiento forzado. Lo anterior debido a que en Colombia este es un tema cuyo abordaje está inacabado tanto por la continuación del conflicto armado como por la existencia de grupos armados ilegales.

Para el reclutamiento forzado en Colombia, como en el resto del mundo, los grupos al margen de la ley han recurrido al uso de la fuerza, el aprovechamiento de situaciones particulares y la vulnerabilidad de los NNA ${ }^{5}$. Así que el reclutamiento por partes de los grupos armados ilegales impacta los derechos, entorno y desarrollo de los niños, niñas y adolescentes; por ende podrían considerarse víctimas. Aunque en el desarrollo del conflicto armado ellos pueden ubicarse en zonas grises como la de víctima-victimarios, lo cual será desarrollado más adelante.

Situaciones como la sociabilidad compartida, que hace referencia a las relaciones interpersonales, los significados asociados y las redes sociales autogeneradas en las prácticas asociativas (Aguirre \& Pinto, 2006). Pero para este artículo solo interesa algunos impactos de la relación entre el grupo armado y la población civil, la cual se desarrolla en el segundo apartado. 
Por otra parte, para cumplir el propósito, este artículo, el presente texto está dividido en cuatro enfoques relacionado al reclutamiento forzado de los NNA por grupos armados ilegales

En el primero se considerará el avance normativo internacional sobre dicho reclutamiento y la condición de responsabilidad penal en la normatividad nacional. En el segundo enfoque se hará referencia a las dinámicas socio-políticas que fomentaron el reclutamiento de NNA. En el tercero se caracterizará el reclutamiento forzado y el voluntario para evidenciar tanto la interrelación como las diferencias que existen entre estos. Finalmente, en el cuarto enfoque se considerará a los NNA responsables sociales antes que victimarios en el conflicto armado.

\section{Enfoques normativos sobre el reclutamiento forzado de los NNA}

Para realizar esta aproximación, se considerarán dos enfoques en materia de normatividad sobre el reclutamiento forzado: el primero, a nivel internacional, sobre el rango etario a considerarse; y un segundo debate, a nivel nacional, sobre la condición de víctima responsable. Estos enfoques se deben a que no hay unanimidad, o un concepto universal, que encierre lo que es ser niño o niña debido a la diferencia en el desarrollo de las comunidades y de sus legados culturales. Por lo tanto, en materia normativa una de las mayores dificultades ha sido el enfrentamiento con las diferentes cargas semánticas del concepto niñez o infancia.

Hay una multiplicidad de infancias codificadas culturalmente y definidas por la edad, la etnia, el género, la historia, la ubicación y así sucesivamente; así lo mencionan desde 1995 autores como Ammit-Talai \& Wulff, Jenks, Schwartzman (Citado por Rosen, 2007, p.297). Sin embargo, a continuación se verá lo relativo al debate internacional sobre el rango etario y el nacional sobre los NNA víctimas responsables. 


\section{a. Enfoque internacional sobre el rango etario}

Pese a que la concepción de infancia puede ser abordada desde diferentes variables, en este apartado se considerará a partir de la edad. En países con un mayor nivel de desarrollo, el rango etario para dejar de ser niño o niña varía entre los quince y veinte años. Sin embargo, en el ámbito internacional, la edad establecida como permitida para la vinculación en ejércitos está ligada a:

- Los Protocolos I y II adicionales a los Convenios de Ginebra (1977) hacen referencia a que no serán reclutados para las fuerzas armadas y no se permitirá que participen en hostilidades, respectivamente, cuando sean menores de quince años (CICR, 1977).

- La Convención de los Derechos del Niño (1989) establece "la prohibición de uso y reclutamiento para las personas menores de quince años" (Asamblea de Naciones Unidas, 1989).

- El Estatuto de Roma (1998) de la Corte Penal Internacional, en su artículo ocho, establece como "crimen de guerra reclutar o alistar a personas menores de quince años en las fuerzas armadas nacionales o utilizarlas para participar activamente en las hostilidades" (ONU, 1998).

- En el Convenio 182 de la OIT, el artículo 3 reconoce el reclutamiento forzoso u obligatorio de niños en conflictos armados como uno de las peores formas de trabajo infantil. Y debe decirse que en su artículo dos considera como niños a personas menores de dieciocho años (OIT, 1999).

- En el Protocolo Facultativo de la Convención de los Derechos del Niño relativo a la participación de los niños en los conflicto armados se establece "la prohibición de uso y reclutamiento obligatorio de personas menores de dieciocho años en fuerzas armadas estatales y no estatales” (Asamblea General de Naciones Unidas, 2000).

- En los Principios de París, en su numeral 2.0 refiriéndose al reclutamiento ilegal, se aclara que niño es toda persona menor de 18 años (UNICEF, 2007, p.6). 
Lo anterior evidencia que el establecimiento del rango de edad se ha adaptado según los tiempos —ya que entre 1977 y 2007 se pasó de 15 a 18 años-, y que es una discusión que se ha dado respecto a la protección de los derechos de los niños y las niñas. Esta diferencia etaria presentada en la normatividad internacional es aprovechada para la práctica de reclutamiento de los grupos armados ilegales evadiendo su responsabilidad. Para el caso de Colombia, desde 1999, con la Ley 548 se prohibió el reclutamiento de menores de 18 años $^{6}$. Posteriormente se aceptó que la Corte Penal Internacional pueda adelantar juicios por reclutamiento de NNA en menores de quince años; esto a través de la Ley 742 de 2002 (Congreso de la República, 2002).

Sin embargo, es importante recordar que en materia de Derechos de los Niños y de las Niñas existe un constante ánimo de proteger sus derechos, por lo tanto, rige la norma que les sea más favorable. Así lo establece el artículo 140 de la Ley 1098 de 2006: "las autoridades judiciales deberán siempre privilegiar el interés superior del niño y orientarse por los principios de la protección integral, así como los pedagógicos, específicos y diferenciados que rigen este sistema”.

Para los NNA, "es necesario tener en cuenta que cada etapa en la que ellos y ellas se encuentran, responden a circunstancias particulares dadas por su entorno, y que se manifiestan de distintas formas durante el curso de sus vidas" (Unidad de Víctimas, 2014, p.12). Esta apreciación es importante señalarla en la medida que los grupos armados ilegales no diferencian niños y adolescentes respecto a jóvenes. El concepto de joven "se va ajustando a las condiciones estructurales que tienen que ver con transformaciones” en lo económico, social y cultural (Ferro y Uribe, 1999, p.147).

En la Ley 12 de 1991, artículo 38, Colombia hizo una reserva elevando la edad mínima para reclutamiento militar de 15 a 18 años. Dicha reserva fue levantada en 1996 (Coalico, s.f.), con fines de permitir la incorporación de menores a las Fuerzas Militares, bajo la figura de servicio militar. 
Por consiguiente el concepto de NNA es una construcción social que no se puede homogenizar aunque la normatividad así lo pretenda. Adicionalmente, la Convención del Niño, el Protocolo Facultativo de la Convención de los Derechos del Niño y el Convenio 182 de la OIT, establecen como obligación del Estado evitar el reclutamiento de NNA en cualquier circunstancia. Por eso se abordará seguidamente la normatividad colombiana sobre la responsabilidad de los NNA reclutados forzadamente.

\section{Normatividad nacional sobre la responsabilidad de los NNA reclutados forzadamente}

En Colombia existe un debate en torno a la responsabilidad de los NNA, que siendo víctimas de reclutamiento forzado, participaron en la comisión de algún crimen. En el país, la normatividad sobre los NNA es de carácter protector, considerando la situación de vulnerabilidad dada por su edad. Por ese motivo no se habla de culpabilidad sino de responsabilidad penal.

La normatividad colombiana establece que un NNA, víctima del reclutamiento forzado, pierde esta condición de víctima cuando se desvincula del grupo armado ilegal siendo mayor de edad. Esto lo establecen las leyes 1424 de 2010 y la 1448 de 2011 (Ley de víctimas y Restitución de tierras), en las que reconoce a los NNA como víctimas siempre y cuando se hayan desvinculado siendo menores de edad ${ }^{7}$.

Ley 1424: Por la cual se dicta disposiciones de justicia transicional que garanticen verdad, justicia y reparación a las víctimas de desmovilizados de grupos organizados al margen de la ley. Ley1448: Artículo 3, parágrafo 2: "Los miembros de los grupos armados organizados al margen de la ley no serán considerados víctimas, salvo en los casos en los que los niños, niñas o adolescentes hubieren sido desvinculados del grupo armado organizado al margen de la ley siendo menores de edad" (Ley 1448 de 2011). Sobre desvinculación: Según la ACR, se entiende por desvinculados a los niños, niñas y adolescentes menores de 18 años que en cualquier condición dejan de ser parte de grupos armados organizados al margen de la ley. 
La Sentencia C-069 de 2016 también reconoce víctimas de reclutamiento forzado a quienes hayan ingresado a las Bandas criminales (Bacrim) siendo menores de edad. En este reconocimiento, cuando la desvinculación se efectúe siendo menores, su condición de víctima se mantiene pero no se desconoce la responsabilidad penal a la que están sujetos ${ }^{8}$. Por lo tanto, los NNA estarían ceñidos a las disposiciones que en materia legal existan para los delitos cometidos. La sentencia C-578 de 2002 señala que los NNA poseen un tratamiento especial como inimputables, sujetos a medidas de seguridad y no a penas privativas de la libertad, cuando son encontrados responsables ${ }^{9}$. Posteriormente, en la sentencia C-203 de 2005, la Corte consideró que: "Los niños y niñas vinculados a los grupos armados son víctimas del delito de reclutamiento [por tanto] los niños y niñas desvinculados son considerados víctimas del conflicto. [Pero] dicha condición no los exime per se de toda responsabilidad penal" (Coalico y CCJ, 2009, pp. 47-48).

Por otro lado la Ley 1098 de 2006 (Ley de Infancia y Adolescencia), en lo referente a la responsabilidad penal para adolescentes (entre catorce y dieciocho años), establece no una pena privativa "sino [...] una consecuencia jurídica [...], orientada por finalidades educativas, rehabilitadoras y protectoras” (Corte Suprema de Justicia, 2010). Todo lo anterior teniendo en cuenta que, como lo señala el artículo 192 de esta ley:

$8 \quad$ En el CONPES 3554: "Hay tres tipos de vinculación: 1) reclutamiento activo, que es aquel que se da por la seducción que hacen los Grupos Armados Ilegales- GAI a través de ofertas económicas y adoctrinamiento político o engaño;2) reclutamiento forzado, se da por el caso de secuestro o captura [..]; y 3) vinculación, en donde no existe una estrategia de reclutamiento y el menor decide hacer parte, autónomamente" (DNP, 2008, p.33).

9 Según el Código Penal, artículo 33,"Es inimputable quien en el momento de ejecutar la conducta típica y antijurídica no tuviere la capacidad de comprender su ilicitud o de determinarse de acuerdo con esa comprensión, por inmadurez sicológica, trastorno mental, diversidad sociocultural o estados similares. Los menores de dieciocho años estarán sometidos al Sistema de Responsabilidad Penal Juvenil” (Ley 599, 2000). 
En los procesos por delitos en los cuales los niños, las niñas o los adolescentes sean víctimas el funcionario judicial tendrá en cuenta los principios del interés superior del niño, prevalencia de sus derechos, protección integral y los derechos consagrados en los Convenios Internacionales ratificados por Colombia, en la Constitución Política y en esta ley (Congreso de la República, 2006).

Sobre la responsabilidad penal de NNA reclutados forzadamente, la Corte Suprema de Justicia en el caso de Fredy Rendón del grupo AUC aclara que se debe analizar cada caso individualmente, para evaluar el impacto de posibles factores que influyeron en la comisión del delito ${ }^{10}$. De esta forma la adjudicación de responsabilidad penal debe tener en cuenta tres aspectos:

el carácter especialmente tutelar y protector de los NNA implicados; su condición de víctimas de la violencia política y, el status de protección especial y reforzada que les confiere el Derecho Internacional en tanto menores combatientes. Todo ello sin perjuicio de la coordinación entre las autoridades judiciales competentes y el Instituto Colombiano de Bienestar Familiar, encargados de desarrollar el proceso de protección y reinserción social que ordena la ley (Corte Suprema de Justicia, 2012, p.2)

10 Factores a tener en cuenta para determinar responsabilidad penal: “(a) las circunstancias específicas de la comisión del hecho y (b) las circunstancias personales y sociales del niño o adolescente implicado [...] (c) el grado de responsabilidad que cabe atribuir a los culpables del reclutamiento del menor que impartieron las órdenes, (d) la responsabilidad de quienes[...], han obrado como determinadores de su conducta [...], y (e) la incidencia de estas circunstancias sobre la configuración de los elementos de tipicidad, antijuridicidad y culpabilidad necesarios para la existencia de un delito. También habrá de determinarse en cada caso individual (f) si es posible, [...], que su comportamiento configure un determinado delito político a pesar de haber sido reclutado, si fuere el caso, en forma contraria a su voluntad, así como (g) la relación entre la configuración de estos delitos políticos y la posible responsabilidad penal que proceda por los delitos conexos, al igual que (h) las conductas que quedarían excluidas de su órbita.” (Corte Suprema de Justicia, 2012, p. 2). 
Sin perder de vista que es primordial proteger a los NNA en su desarrollo físico y psicológico, la Convención sobre los Derechos del Niño incentiva a los países a que se establezcan medidas alternativas al momento de establecer una pena. Por ejemplo, cuando menciona en el artículo 37 que:

[L]a privación de libertad, incluidas la detención, el encarcelamiento o la prisión, se utilizará tan solo como medida de último recurso y durante el período más breve que proceda, a fin de garantizar y respetar plenamente el derecho del niño al desarrollo. (Comité de los Derechos del Niño, 2007, pp. 5-6)

En el debate sobre la responsabilidad penal de los NNA, que al ser víctimas del reclutamiento forzado se le atribuye la comisión de algún crimen, prima la condición de vulnerabilidad. En síntesis, el reclutamiento forzado de NNA es un tema que constantemente se está ajustando en la normatividad internacional como la nacional, aunque debe decirse que se han logrado importantes avances en materia de protección a los NNA en contextos de conflicto armado. Sobre nuestro caso nacional es relevante decir que el reclutamiento forzado es una realidad compleja dadas las características de los grupos armados ilegales, las Bacrim y las dinámicas del conflicto armado según la región y sus pobladores.

\section{Enfoque de las dinámicas socio-políticas del reclutamiento de NNA}

El reclutamiento forzado de los NNA ha transformado las dinámicas de las comunidades en las que se ha dado, pero este apartado hace referencia solo a tres de dichas dinámicas: la rebelocracia, la duración del conflicto y la situación familiar.

La primera dinámica hace alusión a que el reclutamiento forzado de NNA se ha intensificado por la presencia de los grupos armados ilegales en un territorio. Esto se debe a que de los grupos ilegales, uno se 
convierte en una figura de poder. A esta situación se conoce como rebelocracia, ya que dicho grupo es relacionado con una aparente seguridad, orden y tranquilidad en un territorio ${ }^{11}$. La situación, como señala Arjona (2011), resulta muy atractiva especialmente para los jóvenes; un sector de la población para el que el reconocimiento de sus pares (y del sexo opuesto) es una de sus prioridades. De esta forma, para los NNA resulta atractivo participar en ese aparente esquema de seguridad y de autoridad.

La rebelocracia impacta algunas prácticas económicas, políticas y sociales de la comunidad. Respecto a la económica esta se ve afectada, por un lado, por el dominio de tierras y, por el otro, por la imposición de actividades económicas; por ejemplo la sustitución de cultivos tradicionales por ilícitos. En cuanto a la política, el grupo armado ilegal ejerce influencia (directa o indirecta) sobre quienes representan el gobierno; buscan formas de deslegitimarlo o aprovechase de la debilidad institucional para imponer un dominio acorde a sus intereses. Por ejemplo, "las Farc-Ep pudieron actuar como una autoridad local, en algunos casos regionales, que proveía distintas modalidades de orden y formas rudimentarias de justicia” (Aguilera, citado por Gutiérrez, 2015, p. 18).

En cuanto a la práctica social, cotidiana y colectiva, el reclutamiento afecta esta dimensión en la medida que se ve transformada por el conflicto armado cuando lo que se entendía como privado se vuelve público. Es decir que el cuerpo pasa a ser pertenencia del grupo armado ilegal. Por ejemplo, una casa puede ser usurpada, pueden sacar a los niños y niñas de sus camas para ir a entrenamiento, así como restringir las relaciones con otros familiares o con amistades. En esa transformación de costumbres los más afectados son los NNA, quienes ahora

11 Rebelocracia hace referencia a un orden cuando "el grupo armado opera como el gobernante de hecho, regulando conductas que van más allá del pago de contribuciones y del orden público, interviniendo en los ámbitos económico, político y social” (Arjona, 2011). 
construyen su identidad en una comunidad desarraigada del ambiente familiar y escolar. En medio del conflicto armado la confusión de valores y de nuevos papeles implica que los NNA crezcan en ambientes de venganza, desesperanza, miedo, abandono o de escape.

La segunda dinámica, que ha incidido en el reclutamiento forzado de los NNA, es la duración del conflicto armado interno. En la construcción de comunidad varias generaciones han recibido un legado familiar de un pasado de desplazamiento, desapariciones forzadas, amenazas, violaciones a la intimidad, entre otras. Por eso, "como las identidades colectivas son [intergeneracionales], las cadenas y los ciclos de la venganza y de la enemistad, y las guerras mismas pueden comprometer varias generaciones" (Orozco, 2003, p.30). Esta transgresión en la construcción de comunidad ha generado una predisposición frente a los grupos armados o a la institucionalidad. También genera polarización en las comunidades y hasta fragmentación de las familias, ya que cada cual asume una postura de acuerdo a su experiencia. Otro aspecto de la duración del conflicto es la presencia prolongada de un grupo armado ilegal en un territorio. Esta presencia es entendida culturalmente como permitida, atractiva o normal.

Según un estudio realizado con desmovilizados de grupos armados ilegales, más del $90 \%$ de todos los que se unen a un grupo guerrillero lo hicieron mientras vivían en una zona donde uno de estos grupos estaba presente; y más del $60 \%$ de los que se unieron a los paramilitares lo hicieron en áreas sometidas a su presencia (Arjona y Kalyvas, 2008, p.15). ${ }^{12}$ En este contexto huir del reclutamiento forzado es casi imposible, ya que es un medio del grupo armado ilegal para mantenerse en un territorio y conservar su dominio. Por eso, "en momentos en el que su ejército se ve reducido, las Farc-EP no hubieran tenido la

12 Desmovilizado es "Aquel que por decisión individual abandone voluntariamente sus actividades como miembro de organizaciones armadas al margen de la ley, esto es grupos guerrilleros y de autodefensa, y se entregue a las autoridades de la República” (Decreto 128 de 2003). 
menor capacidad de sobrevivir si no hubieran tenido simultáneamente una altísima capacidad de reclutamiento" (Isaza y Campos, citados por Gutiérrez, 2015, p.29). Siendo así, los NNA son presa fácil para los fines del grupo ilegal, porque su poder se impone trasgrediendo todos los espacios y la cotidianidad de esta población.

La tercera dinámica que incide en el reclutamiento forzado es la situación familiar. En este juega un papel determinante la cotidianidad de la familia, ya sea por su difícil situación económica o por las prácticas de violencia doméstica. Por ejemplo, algunas familias se ven obligadas a que sus hijos tengan que trabajar para aportar dinero. En el segundo caso, para salir de un ambiente de violencia intrafamiliar el reclutamiento se convierte en un oportunidad; más aún cuando existen antecedentes de violencia sexual, trabajo infantil o, incluso, cuando un miembro de la familia pertenece a un grupo armado ilegal (Defensoría del Pueblo, 2014, p.27).

También en la dinámica familiar pueden incluirse aspectos personales que inciden en el reclutamiento forzado, por ejemplo, el sentimental y el simbólico. En el sentimental

se ingresa al gremio de los actores de guerra por despecho, por un amor perdido o, al contrario, en aras de no desatender a la persona de sus afectos. En esa última situación pueden presentarse dos eventos: el enamoramiento calculado y/o forzado del individuo, y/o el alistamiento del compañero(a) (Álvarez, citado por Moreno, 2010, p.459).

Por su parte, en el aspecto simbólico, la construcción de la realidad de los NNA es impactada por el bombardeo mediático del héroe y de la guerra como una experiencia fantástica. En efecto, "el poder también se concibe como una aventura: algunos menores han afirmado haber ingresado a uno u otro grupo armado por el ideal que representan esos grupos y por la 'vida de campamento' asociada con la aventura” (Romero y Chávez, 2008, p.201). Si a un NNA se le da a elegir entre un poder 
aventurero y uno heroico o permanecer en una situación de tensión familiar o en una condición económica difícil, es muy probable que se incline por la ficción de poder.

Debido a la condición en la que se encuentran las personas en su minoría de edad, ellos no pueden distinguir la realidad de la fantasía y, sobre todo, no dimensionan las consecuencias de su participación en ese mundo imaginario. Este juego de fantasía-realidad es utilizado por grupos armados ilegales como atractivo para engrosar sus filas, porque "la conciencia del estatus de respeto de aquellos que se involucran y del estatus personal mejorado una vez se han enrolado es atractiva” (Brett y Specht, 2005, p.72).

Otro aspecto personal, que incide en el reclutamiento forzado, es ocasionado la falta de reflexión; esto por ser los NNA una población vulnerable debido a su condición de madurez y su desarrollo. Si bien este aspecto está claramente asociado con el conflicto armado, "no se trata de ideas o de valores que hagan parte de una toma de decisión consciente, sino de una decisión impulsiva” (Pieschacón, Melguizo y González, 2006, p.70).

El reclutamiento forzado resulta siendo una problemática compleja en cada región o en cada comunidad porque se vive de forma diferente el conflicto armado. Es importante no establecer generalidades frente al reclutamiento forzado de NNA porque, como se mencionó anteriormente, cada ser humano se construye a partir de sus experiencias personales. Como se verá a continuación, las dinámicas anteriormente referidas llevan a plantear la difusa línea que existe entre reclutamiento forzado y el voluntario. 


\section{Diferencia de enfoques entre el reclutamiento forzado y el voluntario}

Sobre el reclutamiento de NNA se consideran tres modalidades: obligatorio, forzado o voluntario (Hinestroza, 2008, p.48). Sobre el reclutamiento obligatorio se puede decir que es aquel practicado por las fuerzas armadas nacionales de acuerdo con lo dispuesto en su legislación interna. En Colombia las Fuerzas Militares incorporaban jóvenes menores de edad cuando terminaban sus estudios de secundaria, y esto se realizaba por medio de la figura del Servicio Militar Obligatorio. Esta situación estaba permitida por la Ley 418 de 1997, pero la Ley 548 de 1999 la modificó en su Artículo trece: "Los menores de 18 años de edad no serán incorporados a filas para la prestación del servicio militar" (Congreso de la República, 1999).

Ahora bien, vale precisar que en este apartado se caracterizará el reclutamiento voluntario y forzado, pues son estas modalidades las que guardan relación directa con los objetivos de los grupos armados ilegales.

Debido a la vulnerabilidad — social, política, cultural, económica- de los NNA su reclutamiento es una oportunidad para los grupos armados ilegales, pues dadas sus condiciones radica "la posibilidad de construir un cuerpo con disposición física para la guerra y de construir un habitus guerrero" (Niño, 2014, p.83). La entrega del cuerpo para el cumplimiento de los fines del grupo ilegal, disminuye la autonomía de la persona reclutada como individuo para regirse por la dinámica de ese grupo.

En esta dinámica, una de las características más relevantes del reclutamiento es la invisibilización del sujeto y la visibilización de la colectividad. Esto busca una homogenización del pensamiento de los NNA que esté acorde con la ideología impuesta, ya que con el reclutamiento se pierde la individualidad y se maximiza la experiencia como un ser 
colectivo. Según anota Pachón (2009), los adultos, generalmente, consideran que los niños, niñas y adolescentes son maleables porque es fácil ejercer sobre ellos dominio y autoridad; y en ese mismo sentido, pueden adquirir más riesgos y asumir tareas que los adultos no quieran realizar. Aunque estas son algunas motivaciones para que el reclutamiento se convierta en una práctica habitual en situaciones de conflicto armado, es necesario profundizar en la caracterización y diferenciación entre el reclutamiento forzado y el ingreso voluntario.

\section{a. Reclutamiento forzado}

El reclutamiento forzado hace referencia a la vinculación de menores a los grupos armados ilegales. Debido a la complejidad de este crimen de guerra, la Sentencia C-240 de 2009 aclara que el reclutamiento forzado debe entenderse como:

[...] no solo la participación directa en las hostilidades o actividades de combate, sino que también cubre la participación activa en actividades relacionadas con el combate, tales como reconocimiento, espionaje, sabotaje y el uso de niños como señuelos, correos o en retenes militares. Otros aspectos, como la utilización de niños o niñas como cocineros, mensajeros, para fines de explotación sexual, operadores de radio, etc., ha sido considerado por algunos doctrinantes como parte de esa "utilización" proscrita, aunque el alcance concreto de la expresión todavía es objeto de debate, no obstante su deber de penalización (Corte Suprema de Justicia, 2009).

El conflicto armado en algunas regiones de Colombia ha permitido la consolidación de grupos armados ilegales. El régimen del terror por parte de estos grupos, y la ausencia de mecanismos efectivos de protección a la población, ha convertido al reclutamiento forzado en un medio para dicha consolidación de los grupos. Por esto, como señala la Coalición contra la vinculación de niños, niñas y jóvenes al conflicto armado en Colombia (Coalico), esta problemática responde a falencias estructurales del estado colombiano que no garantiza el goce efectivo 
de los derechos fundamentales de la población infantil y que se ha visto agudizada por la persistencia del conflicto armado.

Considerando que la protección de los NNA es una responsabilidad no solo del Estado sino de la comunidad, por el incumplimiento de tal responsabilidad los NNA son vulnerables al reclutamiento por parte de los grupos armados. Así el carácter de forzado puede ampliarse no solo a que se configure como el resultado del uso de la fuerza, sino de una situación en la que no se garantizó protección a los menores:

La problemática de niñas, niños y adolescentes (NNA) que han hecho parte de los grupos armados no comienza ni termina con su vinculación a ellos, hunde sus raíces en la situación que enfrentan las familias y las comunidades de origen y en las limitadas condiciones que estas les ofrecen a sus miembros para su desarrollo (Cifuentes, 2008, p.3).

Debido a la prolongada presencia de grupos armados ilegales en algunas regiones del país, existe una mayor posibilidad de ser víctima de reclutamiento forzado. Es por ello que los NNA están expuestos a ser vinculados a los grupos ilegales como requisito para conservar su vida y/o la de su familia. La cotidianidad de la violencia lleva a los NNA a una lógica de "ganarse el derecho a vivir [...] una defensa cotidiana de la vida frente al derecho de muerte imperante en el sistema de guerra" (Pieschacón, 2006, p. 47). En esta condición de coacción, dicho grupo le impone a los NNA una doctrina que deben seguir, un grupo que deben defender con su vida y unas actividades que deben realizar.

De esta forma los NNA son obligados a distintas actividades: armadas y/o de combate, de vigilancia, como informantes o campaneros, de apoyo logístico (cocina, lavado de ropa, transporte), tráfico de sustancias ilícitas, inducción al reclutamiento y utilización de otros NNA; mensajería o transporte de suministros, armas o artefactos de cualquier índole; así como tareas de extorsión, hurtos y sicariato (Defensoría del Pueblo, 2014). 


\section{b. Reclutamiento voluntario}

El otro tipo del reclutamiento de NNA, relacionado con los objetivos de los grupos armados ilegales y a su vez el más polémico, es el voluntario. Este supuesto reclutamiento voluntario supone una decisión consciente por parte de los niños, niñas y adolescentes de vincularse a un grupo armado ilegal. Esta decisión, como bien analiza Hinestroza (2008), es resultado de la vulnerabilidad de los NNA en situaciones de pobreza, abuso, discriminación y exclusión (48).

Como se explicó en el apartado anterior, la vinculación de NNA a un grupo armado ilegal es una posibilidad de supervivencia para las familias pobres y numerosas ${ }^{13}$. Esta vinculación que puede ser una fuente de ingreso para sus familias, surge como determinante del carácter de voluntario: "es raro ver a los soldados sin comida. Incluso después de que la población civil está desposeída y con hambre, los soldados armados pueden vivir razonablemente bien” (Brett, 2005, p.60).

La decisión de los NNA de vincularse a un grupo armado ilegal, incluye otros factores mencionados en uno de los informes de la Organización de las Naciones Unidas (2009):

La búsqueda de protección, la supervivencia, el deseo de venganza o el afán de sentirse parte de un grupo después de haber perdido su hogar o a miembros de su familia, también impulsan algunas veces a los niños a unirse a los grupos armados. Para algunos de ellos, la falta de mecanismos legítimos de participación o disensión política o su adhesión a ideologías

El Protocolo Facultativo de la Convención sobre los Derechos del Niño relativo a la participación de niños en los conflictos armados (2000), en su artículo 4, establece que el reclutamiento voluntario debe tener el consentimiento informado de los padres o de sus representantes. En dicho consentimiento reconocen estar completamente informados de los deberes involucrados en tal servicio militar y entregan prueba confiable de su edad antes de aceptársele dentro del servicio militar nacional. 
nacionalistas o de identidad étnica pueden ser factores de motivación muy fuertes. (Reyes, 2013, p.40)

Sin embargo, para algunos investigadores no se puede hablar de reclutamiento voluntario porque los NNA siempre están condicionados por una situación externa, sea social o económica, que los lleva a tomar esa decisión. En una comunidad, en medio de un conflicto armado, tener un arma puede ser considerado símbolo de poder y respeto o de temor; esto porque el solo hecho de portarla abre puertas de casas, entrega dinero, entrega hijos e hijas y posibilita transportes. En las regiones del conflicto el poder no está en la autoridad legítima, así esta sea elegida democráticamente, sino en la intimidación generada por medio de las armas.

Finalmente en el reclutamiento hay una delgada línea que separa lo forzado y lo voluntario. Para comprender las motivaciones de uno y otro es necesario detenerse en la situación particular de cada NNA; es decir, en los contextos económicos y familiares que reflejan de la exclusión social de ciertas comunidades en el país. Esta apreciación es relevante en la medida que debe reconocerse que formar parte de un grupo afecta la construcción de toda identidad. Es por ello que los NNA son susceptibles de manipulación para los fines del grupo armado ilegal.

\section{Enfoque sobre la responsabilidad de los NNA víctimas del reclutamiento}

Quedó dicho que el reclutamiento de NNA es forzado porque existieron circunstancias, desde lo personal a lo institucional, que condujeron a su vinculación a un grupo armado ilegal. Es por ello que en el reclutamiento forzado se debe considerar a los NNA responsables sociales antes que victimarios; lo cual es el foco de este apartado. Sin embargo los NNA que participaron en la comisión de algún delito, por la imposición del grupo ilegal, tienen una responsabilidad penal, como ya mencionamos anteriormente. En un proceso de verdad, justicia, reparación 
y no repetición, la víctima de reclutamiento forzado debe reconocer, entonces, su responsabilidad social.

En el contexto de conflicto armado se entiende al victimario como una persona o una colectividad que ha causado sufrimiento y daño a otra, todo con el objetivo de evidenciar una intención de poder. De acuerdo a la Sentencia C-203 de 2005, los NNA víctimas del reclutamiento forzado no son considerados victimarios; además, en cualquier análisis que se haga en materia del reclutamiento forzado el rango de edad es fundamental.

En ese mismo contexto, es importante aclarar que la condición de cada NNA vinculado al grupo armado ilegal es diferente, porque la situación que generó su reclutamiento así lo evidencia. Una perspectiva de análisis puede ser la de Primo Levi, quien diría que

esa situación de víctima y de victimario puede ser entendida como una disposición [que] está teñida de infinitos matices y motivaciones: terror, seducción ideológica, imitación servil del vencedor, miope deseo de poder (aunque se trate de un poder ridículamente limitado en el espacio y en el tiempo), vileza e, incluso, un cálculo lúcido dirigido a esquivar las órdenes y las reglas establecidas (Citado por Vargas, 2014, p.42).

Por lo tanto no se podría decir que todos los NNA se vincularon de manera forzada, como que no todos son victimarios, pues se vieron motivados por una ideología o un sentimiento de venganza. Entender la condición de cada caso implica un análisis del contexto del individuo previo al reclutamiento, así como del grupo armado ilegal al que se vinculó.

Sin desconocer el carácter de víctima es necesario que se establezca una responsabilidad no solo de carácter penal, sino social, de quienes siendo NNA fueron reclutados forzadamente y cometieron actos en contra de la ley. Esto, porque se suele tratar a los NNA como "receptores pasivos 
de la agencia de adultos, las víctimas de guerras libradas por otros y de brutalidad ajena e impuesta [Es decir que] la voluntad personal es negada y se enfatiza en su vulnerabilidad y desamparo" (Boyden y Berry, 2005, pp. 11-12). La normatividad sobre los NNA es de carácter benefactor y protectora, ya que posee características positivas en materia de reconocimiento de Derechos Humanos; características que son insuficientes para proteger la condición de vulnerabilidad propia de esa edad.

Es necesario que los NNA, en su construcción de identidad, "se reconozcan como sujetos de derechos, así como ciudadanos y artífices de su propio proceso de reparación y reintegración” (Correa, 2014, p.31). En dicho proceso los NNA deben aceptar los hechos pasados y su grado de responsabilidad, aun si solo se les considera víctimas. Aquella responsabilidad debe ser producto de su reconocimiento como un actor social, de su autonomía y del pleno ejercicio de sus libertades. De esta forma los NNA no solo aceptarían el daño causado (responsabilidad penal) sino que harían parte de la reparación y de la no repetición (responsabilidad social). Una reparación que sería en doble vía: al reparar al otro se repara a sí mismo.

Existen NNA desmovilizados conscientes del daño producto de sus acciones y las del grupo armado ilegal al que pertenecieron. Esta condición para muchos de ellos conlleva una gran carga psicológica, e incluso moral; esto se debe a que antes de ser señalados victimarios ellos mismos se reconocen de esta forma. Son relevantes las señalizaciones al respecto realizadas hasta ahora, ya que los procesos de reflexión de los NNA, a partir de la experiencia en las filas de los grupos ilegales, determinan el impacto de los procesos de desmovilización y reintegración.

La culpa de los NNA podría ser tal que no se sientan dignos de participar en una comunidad y terminen aislándose o perteneciendo a otro grupo armado ilegal o a bandas criminales. Esa culpa proviene de la responsabilidad que también "reconoce los límites humanos que había 
olvidado, se coloca justo en el lugar de lo real en el cual se quiere estar" (Hurtado, 2008, p.14). Los NNA, que cometieron delitos durante su vinculación, no pretenden que la comunidad olvide lo que hicieron sino que, en tanto ellos han reconocido su autoría, puedan participar en procesos de esclarecimiento de la verdad y así en su reintegración:

Si la definición es la del niño capaz de empoderarse de su historia y de su rol social (definición responsabilizante), la estrategia será restituirle sus derechos y comprometerlo, como sujeto ético, a que devenga su accionar en el de un actor social protagónico [de] su propio proceso de retorno a la vida civil. (Carmona, 2014, p.173)

El resultado de conocer las experiencias e impresiones de los NNA reclutados permite reconstruir su memoria y una reintegración positiva a la comunidad. En ocasiones pareciera que es tal el impacto del reclutamiento en los NNA que sus imaginarios, ideales y valores son diferentes, producto de lo que vivieron, y estos son guardados en silencio. Aparece una dicotomía para los NNA entre el pasado, que brindaba un espacio y unas reglas de juego conocidas, y un futuro en el que son señalados y en el que su porvenir es incierto. Dicotomía que puede poner en riesgo su proceso de reintegración, ya que abre la posibilidad de retornar a un grupo armado ilegal.

Considerando esta posibilidad de retoro, tanto las organizaciones no gubernamentales como el Estado han buscado brindar las herramientas y programas necesarios para minimizar este riesgo ${ }^{14}$. Un ejemplo de ello es que a nivel estatal y gubernamental se ha avanzado en una

14 No gubernamentales: Aldeas Infantiles SOS, Visión Mundial y la Coalico (reúne otras ocho organizaciones). A nivel estatal: Alta Consejería de la Presidencia para la Reintegración, ICBF y Comisión Intersectorial para la Prevención del Reclutamiento, la utilización y la violencia sexual contra NNA, entre otros. En programas y otras iniciativas existen: la Comisión Intersectorial para la Prevención del Reclutamiento, la utilización y la violencia sexual contra NNA, el Programa 
política pública que busca evitar el reclutamiento forzado de los NNA y un mejor manejo de su impacto. Lo anterior se ha realizado a partir de reconocer que los NNA vinculados al conflicto armado tienen una mayor desprotección, ya que, en términos políticos, no son actores decisivos pues las solicitudes o demandas deben hacerlas a través de una persona adulta. La oportunidad de obtener un beneficio de aquel adulto restringe la visibilidad de las necesidades de los NNA. Es por ello que algunas organizaciones no gubernamentales han asumido de manera activa algunas estrategias para apoyar el proceso de reintegración. Esto lo han llevado a cabo integrando a sus agendas y en programas dichas estrategias, como son los procesos de conciliación en los colegios, capacitaciones con fines productivos y actividades artísticas.

En lo estatal existen varios factores que afectan a los programas de desvinculación de NNA, algunos de ellos son "alcanzar la mayoría de edad en medio de la Ruta de Reintegración Social; el miedo; la desconfianza frente a otros excombatientes y a personas desconocidas, por la posibilidad de ser infiltradas; el miedo de ser rechazados por su pasado" (Rethmann, 2010: 10); a lo cual además se le suma el bajo nivel de credibilidad a la institucionalidad. Por esto es importante desarrollar paralelamente al proceso psicosocial, que adelanta el ICBF, programas comunitarios que cambien los imaginarios hacia los NNA desvinculados.

Los NNA deben, paulatinamente, asumir liderazgos que les faciliten no solo su reintegración sino el reconocimiento de responsabilidades en medio del conflicto armado. Esta dinámica esta orienta por la idea de que "el perdón recíproco y la reconciliación solo se logran cuando los antiguos vengadores se reconocen $-\mathrm{y}$ la sociedad los reconoce- como víctimas y victimarios, simultáneamente inocentes y culpables" (Orozco,

Especializado de Atención a Menores Desvinculados de Grupos Armados Ilegales, el Programa Presidencial de DDHH y DIH, el Sistema de Alertas Tempranas, Mis Derechos Primero, entre otros. 
2003, p.43). El proceso de perdón debe culminar con la superación de sentimientos como la culpa, la venganza y el miedo en los que están inmersas las víctimas de reclutamiento forzado. Como se mencionó anteriormente, los NNA no pudieron elegir porque fueron obligados a vincularse al grupo armado ilegal.

Por consiguiente el proceso de reintegración y de reconciliación debe darse tanto con los NNA desvinculados como con la comunidad para que haya una mejor comprensión de la situación. Solo así se romperán los paradigmas que se han construido en torno al conflicto armado, el cual llevó a una categorización de las personas quienes fueron etiquetadas con un papel o con un grupo armado ilegal desconociendo su característica primordial como seres humanos: "lo imperioso es crear una sociedad en la que la realidad de la diversidad humana, sea personal, orgánica o social, no esté sometida al poder de criminalizar" (Taylor, 1997, p.298). De esta forma se avanza en la recuperación de los valores, la reconstrucción de la familia y de la institucionalidad.

En el sentido integral de reconstrucción de tejidos, la aceptación de la responsabilidad social del NNA es el paso necesario para el perdón y la reconciliación individual y colectiva, pues como señala acertadamente Machel (citado por Ruiz, 2008):

en consecuencia, es indispensable que todas las formas de ayuda externa contribuyan a fortalecer la capacidad de las personas para ayudarse a sí mismas. Por ejemplo, habría que ayudar a los padres y maestros a hablar con los niños de las cuestiones difíciles. La reconstrucción de la red social y un sentido de la comunidad ayudan a las personas a colaborar para mejorar su vida (p.53). 


\section{Consideraciones finales}

Este artículo tuvo como propósito identificar algunos de los enfoques conceptuales y normativos en torno al reclutamiento forzado de NNA por los grupos armados al margen de la ley, y para tal efecto se identifican cuatro focos de discusión. En primer lugar se hizo una aproximación el avance normativo internacional sobre dicho reclutamiento y en la normatividad nacional la condición de víctima responsable. Le siguió un análisis la dinámica socio-política que fomentó el reclutamiento de NNA. En tercer lugar se presentó la diferencia de enfoques entre el reclutamiento forzado y el ingreso voluntario; y, por último, se expuso y analizó el reconocimiento de una responsabilidad social para los NNA que fueron víctimas del reclutamiento forzado.

En el primer enfoque, la normatividad internacional sobre reclutamiento forzado de NNA muestra una disparidad en su limitación etaria. El rango "permitido" para la vinculación a un conflicto armado oscila entre los quince y dieciocho años dependiendo del instrumento internacional que se revise. Sin embargo en Colombia este reclutamiento está prohibido en menores de dieciocho años. En la normatividad nacional, el NNA que haya participado en la comisión de un delito es objeto de responsabilidad penal y no tiene una pena privativa de la libertad. Esto, porque en su judicialización, los NNA son reconocidos como víctimas, inimputables y poseedores de protección especial en materia de Derechos Humanos. Todavía existen algunas reservas en la judicialización cuando se reconoce la participación de ellos en crímenes de lesa humanidad y se ha insistido en que cada caso sea evaluado individualmente.

El segundo enfoque sobre el reclutamiento forzado de NNA presentó cuatro dinámicas socio políticas. Entre estas la rebelocracia, reconocida cuando un grupo armado ilegal impacta las decisiones de la comunidad y, por ende, de los NNA. La segunda es la duración del conflicto armado interno porque los sentimientos de venganza y de miedo son transmitidos en los cambios generacionales. La tercera dinámica se da cuando 
la situación familiar y social impulsa al NNA a huir de un ambiente de violencia intrafamiliar o de pobreza. Por último, la cuarta dinámica está caracterizada por el estado de vulnerabilidad propio de la minoría de edad que afecta el proceso de reflexión y decisión de los NNA.

En el tercer enfoque se diferenció entre reclutamiento forzado y el voluntario de los NNA. En el reclutamiento forzado son invisibilizados frente al grupo armado ilegal, esto dado a partir de la manipulación de los imaginarios construidos de violencia en los juegos bélicos y en los héroes. Mientras que en el En el reclutamiento voluntario se consideró como una acción propia de la toma de decisión. Este último resulta ser discutible porque el NNA no cuenta con plena autonomía ante la situación; su decisión puede ser resultado de situaciones desfavorables de violencia intrafamiliar, una convivencia social problemática o dificultades económicas, entre otras.

Finalmente, el cuarto enfoque abordó el reconocimiento de una responsabilidad social para los NNA que fueron víctimas del reclutamiento forzado; esto analizado desde la perspectiva que señala que al ser víctimas los niños, niñas y adolescentes no pueden ser considerados victimarios. Partiendo de ello, se configura la responsabilidad penal y se reconoce responsabilidad social, en donde los NNA deben cambiar su condición de sujetos pasivos a sujetos responsables. En el proceso de esclarecimiento de la verdad, la justicia y la reparación, su voz debe ser escuchada, no solamente como testimonio sino como principio de su propia reparación. De esta forma, esa responsabilidad reconocida debe ser el punto de partida para la construcción de memoria, la restitución de derechos y su papel activo como ciudadanos(as).

En conclusión los NNA reclutados forzadamente por un grupo armado ilegal son víctimas debido a su carácter de vulnerabilidad propio de su edad. Aunque instrumentos normativos nacionales e internacionales han buscado protegerlos de tal vulnerabilidad, no han sido suficientes los esfuerzos debido a las dinámicas socio-políticas particulares que 
posibilitan dicho reclutamiento. Al ser este reclutamiento una consecuencia del conflicto armado es importante que los NNA se reconozcan como responsables sociales. Ellos deben asumir un papel protagónico en el proceso de reintegración y reparación que permita el desarrollo de ciudadanos(as) reconciliados(as) con su pasado, con su comunidad y con la institucionalidad. En dicho proceso la verdad no se debe quedar solo en los relatos sobre lo ocurrido y lo vivido, ya que la verdad debe convertirse en la oportunidad para construir una sociedad a partir del intercambio de experiencias, la tolerancia, la inclusión y el respeto por un pasado desafortunado.

\section{Referencias}

Agencia Colombiana de Reintegración - ACR (s.f.). ABC de la Ley 1424 de 2010. Elementos esenciales para comprender el diseño y el funcionamiento de la Ley 1424 de 2010. Recuperado de http://www.reintegracion.gov.co/es/lareintegracion/centro-de-documentacion/Documentos/Abec\% C3\% A9\%20 de \%20la \%20Ley\%201424.pdf

. (2016, enero). Desarme, Desmovilización y Reintegración: retos para el caso colombiano -Memorias del curso.

Recuperado de http://www.reintegracion.gov.co/es/la-reintegracion/centrode-documentacion/Documentos/Relatoria \% 20DDR \% 2011 \% 2004 \% 20 16\%20Final.com.pdf

Aguirre, A \& Pinto, M. (2006). Asociatividad, capital social y redes sociales. En Revista Mad, (15) Santiago de Chile: Universidad de Chile, 7492. Recuperado de http://200.89.78.45/index.php/RMAD/article/viewFile/14022/14327

Arjona, A. (2011). De Rebelocracias y Reclutas: Instituciones y Participación en el Conflicto Armado Colombiano. Recuperado de http://focoeconomico. org/2011/04/12/de-rebelocracias-y-reclutas-instituciones-y-participacionen-el-conflicto-armado-colombiano/

Arjona, A. y Kalyvas. S. (2008). Results of a Survey of Demobilized Guerilla and Paramilitary Fighters in Colombia. Recuperado de http://www.anamarjona.net/docs/Arjona_Kalyvas_2008.pdf 
Asamblea General de las Naciones Unidas (2000). Protocolo Facultativo de la Convención de los Derechos del Niño relativo a la participación de los niños en los conflicto armados. Resolución A/RES/54/263. ONU.

Asamblea General de Naciones Unidas (1989, noviembre). Convención de los Derechos del Niño. Resolución 44/25. ONU.

Brett, R. y Specht, I. (2005). Jóvenes soldados y combatientes. ¿Por qué van a luchar? Ginebra: Organización Internacional del Trabajo. Recuperado de http://www.quno.org/sites/default/files/resources/ESPAN \% CC \% 83OL_ Young_soldiers_why_they_choose_to_fight.pdf

Boyden, J. y De Berry, J (Eds). (2005). Childen and Youth on the Front Line: Ethnography, Armed Conflict and Displacement. Londres: Berghahn Books.

Carmona, J. (2014). Definición de la situación de los menores desvinculados de los grupos armados ilegales en los actos jurídicos y sus efectos psicoeducativos. En Estudios Socio-Jurídicos, 16(2), Bogotá: Universidad del Rosario, 163-177. DOI: http://dx.doi.org/10.12804/esj16.02.2014.05

Cifuentes, M. (2008). El Sí y el Otro en la constitución de la identidad: niñas, niños y adolescentes desvinculados del conflicto armado. Trabajo social, (10), 9-27. Recuperado de https://dialnet.unirioja.es/descarga/articulo/4386094.pdf

Coalición contra la Vinculación de Niños, Niñas y Jóvenes al Conflicto armado en Colombia y Comisión Colombiana de Juristas (2013). El Delito Invisible. Criterios para la investigación del delito de reclutamiento ilícito de niños y niñas en Colombia. Bogotá: Coalico y CCJ.

Coalición contra la Vinculación de Niños, Niñas y Jóvenes al Conflicto armado en Colombia (s.f.). Niños, Niñas y Jóvenes en Conflicto Armado Análisis Jurídico Legislación Internacional y Colombiana. Recuperado de http:// www.coalico.org/publicaciones/legislacion.htm

Comité de los Derechos del Niño, Observación General No. 10. Los derechos del niño en la justicia de menores, CRC/C/GC/10, 25 de abril de 2007, párr. 11 .

Comité Internacional de la Cruz Roja (1977, Junio). Protocolo I adicional a los Convenios de Ginebra de 1949 relativo a la protección de las víctimas de los conflictos armados internacionales. CICR. 
Comité Internacional de la Cruz Roja - CICR. (1977, Junio 8). Protocolo II adicional a los Convenios de Ginebra de 1949 relativo a la protección de las víctimas de los conflictos armados sin carácter internacional. CICR.

Congreso de la República. (1999, diciembre). Prórroga Ley 418 de 1997. [Ley 548 de 1999].

Congreso de la República. (1999, julio). Código Penal. [Ley 599 de 2000].

Congreso de la República. (2002, junio). Aprobación del Estatuto de Roma de la Corte Penal Internacional. [Ley 742 de 2002].

Congreso de la República. (2006, Noviembre). Código de la Infancia y la Adolescencia. [Ley 1098 de 2006].

Congreso de la República. (2010, Diciembre). Ley de Desmovilizados. [Ley 1424 de 2010].

Congreso de la República. (2011, Junio). Ley de Víctimas y de Restitución de Tierras. [Ley 1448 de 2011].

Departamento Nacional de Planeación (2008, diciembre). Política Nacional de Reintegración Social y Económica para personas y grupos armados legales. Documento CONPES 3554. Bogotá: DNP.

Correa, C., Jiménez, A. Ladisch, V. y Salazar, G. (2014). Reparación integradora para niños, niñas y jóvenes víctimas de reclutamiento ilícito en Colombia. Bogotá: ICTJ. Recuperado de https://www.ictj.org/es/publication/ reparacion-integradora-ninos-reclutamiento-ilicito-colombia.html

Corte Constitucional. (2009, abril). Sentencia C-240 de 2009. Recuperado de http://www.corteconstitucional.gov.co/RELATORIA/2009/C-240-09.htm

Corte Suprema de Justicia. (2010, febrero). Sala de Casación Penal. Proceso No. 32889. Aprobado Acta No. 57.

Corte Suprema de Justicia. (2012, Diciembre 12). Sala de Casación Penal. Sentencia de Segunda Instancia. Justicia y Paz, Radicado 38222. Recuperado de http://www.fiscalia.gov.co/jyp/wp-content/uploads/2012/10/FichaFreddy-Rend \% C3 \% B3n-Herrera-2012-Instancia-2.pdf

Defensoría del Pueblo. (2014). Informe Defensorial Prevención del reclutamiento de niños, niñas y adolescentes. Análisis de la política pública con enfoque étnico. Bogotá: Defensoría del Pueblo. 
Ferro, J., Uribe, G., Osorio, E.; \& Castillo, O. (1999). Jóvenes, coca y amapola. Un estudio sobre las transformaciones socioculturales en zonas de cultivos ilícitos. Bogotá: Javegraf.

Fox, M. (2005). "Child soldiers and international law: Patchwork gains and conceptual debates”. En Human Rights Review, 7(1), 27-48. doi: http:// dx.doi.org/10.1007/s12142-005-1001-4

Gutiérrez, F. (2015). ¿Una historia simple? Recuperado de http://www.centrodememoriahistorica.gov.co/descargas/comisionPaz2015/GutierrezFrancisco.pdf

Hinestroza-Arenas, V. (2008). Reclutamiento de niños y niñas: fenómeno invisibilizado, crimen manifiesto. En Observatorio de Análisis de los Sistemas Internacionales, (13). Bogotá: Universidad Externado de Colombia, 45-60. Recuperado de http://dialnet.unirioja.es/servlet/articulo? codigo = 3986289

Hurtado, D. (2008). "El nómada con conciencia histórica un abordaje del fenómeno de la desvinculación de los niños, niñas y jóvenes del conflicto armado: Una propuesta en y desde el lenguaje”. En Revista Perspectivas en psicología, (11). Manizales: Universidad de Manizales. Recuperado de http://www.umanizales.edu.co/publicaciones/campos/sociales/perspectivas_psicologia/html/revistas_contenido/revista11/Elnomada.pdf

Instituto Colombiano de Bienestar Familiar, Organización Internacional para las Migraciones \& Fondo de las Naciones Unidas para la Infancia. (2014). Impacto del conflicto armado. En el estado psicosocial de niños, niñas y adolescentes. Bogotá: ICBF. Recuperado de http://rni.unidadvictimas.gov. co/sites/default/files/Documentos/IMPACTO \%20CONFLICTO \%20ARMADO \% 20EN \% 20EL \% 20ESTADO \% 20PSICOSOCIAL \% 20DE \% 20NINOS $\% 20$ Y\%20ADOLESCENTES.pdf

Ila, P. A. (2009). Elementos para la conceptualización del reclutamiento, la vinculación y la utilización de niños, niñas y adolescentes en el conflicto armado. En Justicia, (69). Recuperado de http://www.corteidh.or.cr/tablas/r23675.pdf

Lara Salcedo, L. M., y Delgado Salazar, R. (2010). Trasegar de las subjetividades y las memorias de las y los jóvenes desmovilizados en el tránsito a la vida civil. Una mirada a los programas educativos y de apoyo psicosocial. Universitas Humanística, 70(70). Bogotá: Pontificia Universidad Javeriana. 
Recuperado de http://revistas.javeriana.edu.co/index.php/univhumanistica/article/viewFile/2094/1357

Mago, I. (2011). ¿De niño combatiente a ciudadano? Los retos de la reintegración política de niños desvinculados del conflicto armado colombiano. Tesis de Maestría. Universidad de los Andes. Bogotá. Revisado el 18 de febrero de 2015. Recuperado de http://www.reintegracion.gov.co/es/la-reintegracion/centro-de-documentacion/Documentos/De \%20ni \%C3 \% B1o\%20 combatiente \% 20a \% 20ciudadano \% 20Los \% 20retos \% 20de \% 20la \% 20 Reintegraci \% C3 \% B3n \% 20pol \% C3 \% ADtica \% 20de\% 20ni \%C3\% B1os \% 20 desvinculados \%20del\%20conflicto \% 20armado.pdf

Mariño, C. (2012). "Derechos de los niños y niñas reclutados o utilizados en hostilidades en la justicia transicional en Colombia: evoluciones normativas y prácticas jurídicas”. En Criterio Jurídico Garantista, 3(6), 76-97. Recuperado de http://ustamed.leyex.info/magazines/crijurigara64.pdf

McConnan y Uppard. (2001). Children Not Soldiers: Guidelines for Working with Child soldiers and Children Associated with Fighting Forces. Londres: Save the Children.

Mejía, M. (2012) Justicia restaurativa y principio de oportunidad en el sistema de responsabilidad penal juvenil: hacia la reconciliación con la víctima en el marco del conflicto armado. Revista Iter ad Veritatem, 10(10), Tunja: Universidad Santo Tomás, 85-110. Recuperado en http://revistas.ustatunja. edu.co/index.php/iaveritatem/article/view/556/376

Moreno, F., Carmona, J., \& Tobón, F. (2010). “¿Por qué se vinculan las niñas a los grupos guerrilleros y paramilitares en Colombia?” En Revista Latinoamericana de Psicología, 42(3),Bogotá: Fundación Universitaria Konrad Lorenz, 453-467. Recuperado de http://genderandsecurity.org/sites/default/ files/Moreno_Martin_et_al_-_Por_que_se_vinculan_ninas_a_grupos_guerrilleros_paramilitares_en_Colombia.pdf

Niño, N. (2014). De la vida militar a la vida civil de jóvenes excombatientes en Colombia, subjetividades en tránsito: una aproximación desde la infancia, la juventud y el género. (Tesis de Maestría). México: Flacso México. Recuperado de http://bibdigital.flacso.edu.mx:8080/dspace/bitstream/handle/123456789/3555/Nino_NC.pdf?sequence $=1$

Observatorio de procesos de Desarme Desmovilización y Reintegración (2014) Trayectorias de quienes ingresaron siendo menores de edad, después de 
salir de una Organización Armada Ilegal. Bogotá: Universidad Nacional de Colombia, ODDR.

Organización Internacional del Trabajo. (1999, noviembre). Convenio sobre la prohibición de las peores formas de trabajo infantil y la acción inmediata para su eliminación. [Convenio 182]. Ginebra: OIT.

Orozco, I. (2003). La postguerra colombiana: divagaciones sobre la venganza, la justicia y la reconciliación. Working Paper, (306). Kellogg Institute. Recuperado de http://kellogg.nd.edu/publications/workingpapers/WPS/306. pdf iframe $=$ true $\&$ width $=90 \%$ \&height $=90 \%$ ONU. (1998, Julio 17). Estatuto de Roma de la Corte Penal Internacional. Roma: ONU.

Pachón, X. (2009). La infancia perdida en Colombia: los menores en la guerra. Working paper series, (15). Recuperado de http://pdba.georgetown.edu/ CLAS \% 20RESEARCH/Working \%20Papers/WP15.pdf

Pieschacón, F., Melguizo, M. C., y González, P. (2006). Estudio exploratorio de patrones culturales que contribuyen a la vinculación de niños, niñas y jóvenes a los grupos armados en Colombia. En Corporación Alotropía, (69). Bogotá: Corporación Alotropía. Recuperado de http://www.alotropia.org/ docs/NNJ_ConflictoArmado.pdf

Ramírez, P. (2010). El Reclutamiento de Menores en el Conflicto Armado Colombiano: Aproximación al Crimen de Guerra. En Derecho Penal y Criminología, 31(90), 115-136. Recuperado de http://papers.ssrn.com/sol3/ papers.cfm?abstract_id $=1661852$

Rethmann, A. (2010). Condenados al silencio jóvenes excombatientes en Colombia. (Axe XI, Symposium 40). Independencias - Dependencias - Interdependencias. Toulouse: VI Congreso CEISAL. Recuperado de https:// halshs.archives-ouvertes.fr/halshs-00503128/document

Reyes, P. (2013). "Los niños y las niñas como víctimas en los conflictos armados: participación en las hostilidades". En Revista Latinoamericana de Derechos Humanos, 24 (1-2).Heredia: Universida Nacional de Costa Rica, 35-56. Recuperado de http://revistas.una.ac.cr/index.php/derechoshumanos/article/view/5792

Romero, Y. \& Chávez, Y. (2008). "El juego de la guerra, niños, niñas y adolescentes en el conflicto armado en Colombia”. En Revista Tabula Rasa, (8). Bogotá: Universidad Colegio Mayor de Cundinamarca. 197-210. 
Ruiz, Luz Dary. (2008). "Nos pintaron pajaritos": el conflicto armado y sus implicaciones en la niñez colombiana. Bogotá: Instituto Popular de Capacitación (IPC). Recuperado de http://www.choike.org/documentos/ nos_pintaron_pajaritos.pdf

Rosen, D. M. (2007). Child soldiers, international humanitarian law, and the globalization of childhood. En American Anthropologist, 109(2). Philadelphia: University of Pennsylvania, 296-306.

Taylor, I., Walton, P., Young, J. (1997). La nueva criminología: Contribución a una teroría social de la conducta desviada. Buenos Aires: Amorrortu Editores.

Tirado,M. (2013). Niños, niñas y adolescentes en el conflicto armado en Colombia. Revista Verba Iuris, (29). Bogotá: Universidad Libre. 147-159. Recuperado de http://www.leyex.info/magazines/n2920138.pdf

Springer, N. (2012). Como corderos entre lobos, del uso y reclutamiento de niñas, niños y adolescentes en el marco del conflicto armado y la criminalidad en Colombia. Bogotá: Springer Consulting Services. Recuperado de http://www.centrodememoriahistorica.gov.co/descargas/informe_comoCorderosEntreLobos.pdf

UNICEF. (2007). Los principios y directrices de París sobre los niños vinculados a fuerzas o grupos armados. Recuperado de http://www.unicef.org/ spanish/protection/files/pariscommitments.pdf

Unidad para la Reparación Integral de las Víctimas - Unidad de Víctimas (2014). Protocolo para la Participación de Niños, Niñas y Adolescentes cíctimas del Conflicto Armado Colombiano. Recuperado de http://www.unidadvictimas.gov.co/especiales/voces-agudas/docs/protocolo-participacion.pdf

Vargas, S. (2014). La deconstrucción de la dualidad amigo-enemigo en la participación de civiles en el conflicto armado colombiano. (Tesis de Maestría). Universidad Colegio Mayor de Nuestra Señora del Rosario. Bogotá. Recuperado de http://repository.urosario.edu.co/bitstream/handle $/ 10336 / 10125 / 53140394-2015 . p d f$ ? sequence $=1$ \&isAllowed $=\mathrm{y}$

Villadiego, C. (2010). Perspectiva de infancia en las políticas de juzgamiento en las transiciones en Colombia: El caso de los niños, niñas y adolescentes reclutados por grupos armados al margen de la ley. (Tesis de Maestría). Recuperado de 
http://admin.banrepcultural.org/sites/default/files/colf_villadiego_burbano_carolina_tesis.pdf

Wainryb, C. (2011). 'And so they ordered me to kill a person': Conceptualizing the impacts of child soldiering on the development of moral agency. En Human Development, 54(5), 273-300. doi:http://dx.doi.org/10.1159/000331482

Webster, T. (2007). Babes with arms: international law and child soldiers. En The George Washington International Law Review, 39(2). Washington: George Washington University Law School. 227-254.

Wessells, M. (2000). How We Can Prevent Child Soldiering. En Peace Review, 12(3).San Francisco: Universidad de San Francisco. 